\title{
The effect of exogenous nucleosides on postimplantation development of mouse embryos
}

\author{
A. I. Spindle* and R. A. Pedersen*† \\ * Laboratory of Radiobiology and $\dagger$ Department of Anatomy, \\ University of California, \\ San Francisco, California 94143, U.S.A.
}

\begin{abstract}
Summary. Exogenous nucleosides, either singly or in combination, do not enhance postimplantation development of mouse embryos in vitro, and adenosine, guanosine and thymidine are toxic to the embryos at high concentrations.
\end{abstract}

Techniques for culturing postimplantation mouse embryos have advanced in recent years, and it is now possible to grow mouse embryos from the 2-cell or the blastocyst stage to the egg-cylinder stage (Spindle \& Pedersen, 1973; Pienkowski, Solter \& Koprowski, 1974) and even to the early somite stage (Hsu, 1972; Hsu, Baskar, Stevens \& Rash, 1974). However, the nutritional requirements for postimplantation development of mouse embryos are poorly understood, except that amino acids, serum (Gwatkin, 1966; Spindle \& Pedersen, 1973) and glucose (Wordinger \& Brinster, 1976) are required for hatching, attachment and outgrowth of blastocysts. This study was undertaken to determine whether exogenous nucleosides would stimulate development of mouse blastocysts in vitro to postimplantation stages.

Randomly bred Dub: (ICR) mice (Flow Laboratories) were used as the source of embryos. Female mice (6-10 weeks old) were induced to superovulate by injecting 5 i.u. PMSG (Sigma) and 5 i.u. HCG (Ayerst) $48 \mathrm{~h}$ later and were caged with Dub: (ICR) male mice overnight. Two-cell embryos were flushed from the oviducts $45-48 \mathrm{~h}$ after $\mathrm{HCG}$ injection and were cultured in modified standard egg-culture medium (Spindle \& Goldstein, 1975). After incubation for 3 days at $37^{\circ} \mathrm{C}$ in an atmosphere of $5 \% \mathrm{CO}_{2}$ in air, blastocysts were transferred to eight-chamber culture slides (Lab-Tek) (15 embryos/chamber) containing modified Eagle's basal medium (BME) $(0.5 \mathrm{ml} / \mathrm{chamber}$ ), which contains optimal concentrations of essential amino acids (Spindle \& Pedersen, 1973). This medium was supplemented with 1 or $10 \%$ dialysed serum (equal parts of fetal calf serum (GIBCO) and newborn calf serum (Flow Laboratories)) and with various concentrations of adenosine, cytidine, guanosine, thymidine or uridine (Sigma). Before the addition, the serum was dialysed for 3 days in phosphate-buffered saline, which was changed twice each day, to remove any nucleosides that might have been present. Stock solutions of nucleosides were made by dissolving them singly in modified $\mathrm{BME}$ at a concentration of $10^{-2} \mathrm{M}$ (adenosine, cytidine and uridine) or $10^{-3} \mathrm{M}$ (guanosine and thymidine), and series of 10 -fold dilutions were made from the original stock solutions by adding modified BME. The calculated osmolarity of modified BME was 280 mosmol, and the osmolarity of the medium that contained the highest concentration of nucleosides $\left(10^{-2} \mathrm{M}\right)$ was still within the limit that is well tolerated by mouse embryos (240-310 mosmol: A. I. Spindle, unpublished observation).

The growth response of embryos was examined under a dissecting microscope $(\times 140)$ after 5 days of culture, and the number of trophoblast outgrowths, the total number of inner cell masses (ICMs), and the number of ICMs that differentiated into endoderm and ectoderm were counted. Significant differences between control and experimental groups in the number of embryos surviving to these three morphological endpoints were determined by Student's $t$ test.

When each nucleoside was added alone (Table 1), none stimulated development of embryos at any of the concentrations tested and thymidine, guanosine and adenosine were toxic at high concentrations. At concentrations of $10^{-5} \mathrm{M}$ and higher, thymidine reduced the total number of ICMs and the number of ICMs with two germ layers $(P<0.01)$ but it did not affect trophoblast outgrowth, even at $10^{-3} \mathrm{M}$. By contrast, guanosine reduced the number of trophoblast outgrowths $(P<0.05$ for 
Table 1. Effects of individual nucleosides on the development of postimplantation mouse embryos (15 blastocysts for each concentration of nucleoside; 4-9 replicate experiments)

\begin{tabular}{|c|c|c|c|c|c|c|}
\hline \multirow{2}{*}{$\begin{array}{l}\text { Nucleoside and } \\
\text { developmental } \\
\text { endpoint }\end{array}$} & \multicolumn{6}{|c|}{$\begin{array}{c}\text { Mean no. }( \pm \text { S.E.M.) of embryos developing to endpoints } \\
\text { for various nucleoside concentrations }(M)\end{array}$} \\
\hline & 0 & $10^{-6}$ & $10^{-5}$ & $10^{-4}$ & $10^{-3}$ & $10^{-2}$ \\
\hline \multicolumn{7}{|l|}{ Adenosine } \\
\hline Trophoblast outgrowth & $14 \cdot 3 \pm 0 \cdot 8$ & $14 \cdot 2 \pm 0.8$ & $14 \cdot 5 \pm 0.6$ & $14.5 \pm 0.6$ & $14.8 \pm 0.5$ & $11 \cdot 8 \pm 2.6$ \\
\hline Total ICMs & $11 \cdot 8 \pm 1 \cdot 7$ & $11 \cdot 6 \pm 3 \cdot 1$ & $13 \cdot 0 \pm 0.8$ & $12.5 \pm 0.6$ & $9 \cdot 8 \pm 2 \cdot 4$ & $3 \cdot 0 \pm 1 \cdot 6 * *$ \\
\hline ICMs with 2 germ layers & $5 \cdot 5 \pm 2 \cdot 6$ & $4 \cdot 8 \pm 2 \cdot 8$ & $6 \cdot 0 \pm 2 \cdot 8$ & $4 \cdot 3 \pm 1.9$ & $3 \cdot 5 \pm 1 \cdot 7$ & $0^{* *}$ \\
\hline \multicolumn{7}{|l|}{ Guanosine } \\
\hline Trophoblast outgrowth & $14 \cdot 0 \pm 1 \cdot 1$ & $14 \cdot 0 \pm 0 \cdot 7$ & $13 \cdot 5 \pm 1 \cdot 1$ & $10 \cdot 2 \pm 2 \cdot 7^{*}$ & $4 \cdot 2 \pm 0 \cdot 8^{* *}$ & - \\
\hline Total ICMs & $12 \cdot 3 \pm 1 \cdot 5$ & $11 \cdot 4 \pm 1 \cdot 7$ & $9 \cdot 2 \pm 2 \cdot 3$ & $2 \cdot 6 \pm 1 \cdot 7 * *$ & $0.8 \pm 1.3^{* *}$ & - \\
\hline ICMs with 2 germ layers & $5 \cdot 2 \pm 1 \cdot 3$ & $4 \cdot 8 \pm 0.5$ & $2 \cdot 8 \pm 2 \cdot 6$ & $0 * *$ & $0^{* *}$ & 一 \\
\hline \multicolumn{7}{|l|}{ Cytidine } \\
\hline Trophoblast outgrowth & $14 \cdot 2 \pm 0.9$ & $14 \cdot 1 \pm 1 \cdot 0$ & $14 \cdot 4 \pm 1 \cdot 1$ & $14.6 \pm 0.6$ & $13 \cdot 8 \pm 1 \cdot 8$ & $14 \cdot 4 \pm 1 \cdot 3$ \\
\hline Total ICMs & $11 \cdot 1 \pm 1 \cdot 9$ & $11 \cdot 5 \pm 1 \cdot 2$ & $12.1 \pm 1.9$ & $14 \cdot 2 \pm 1 \cdot 3$ & $12 \cdot 4 \pm 2 \cdot 0$ & $11 \cdot 4 \pm 1 \cdot 7$ \\
\hline ICMs with 2 germ layers & $5 \cdot 1 \pm 1 \cdot 5$ & $5 \cdot 3 \pm 1 \cdot 4$ & $6 \cdot 6 \pm 2 \cdot 5$ & $7 \cdot 0 \pm 2 \cdot 6$ & $4 \cdot 8 \pm 2 \cdot 6$ & $2.8 \pm 1.9$ \\
\hline \multicolumn{7}{|l|}{ Uridine } \\
\hline Trophoblast outgrowth & $14 \cdot 2 \pm 1 \cdot 0$ & $14.0 \pm 0.9$ & $14 \cdot 3 \pm 0.5$ & $14 \cdot 0 \pm 0.7$ & $14.5 \pm 0.6$ & $13 \cdot 3 \pm 1 \cdot 9$ \\
\hline Total ICMs & $12 \cdot 2 \pm 1 \cdot 0$ & $12 \cdot 7 \pm 1 \cdot 2$ & $13.8 \pm 1.0$ & $13 \cdot 2 \pm 1.8$ & $13 \cdot 3 \pm 2 \cdot 2$ & $11 \cdot 3 \pm 2 \cdot 7$ \\
\hline ICMs with 2 germ layers & $5 \cdot 2 \pm 2 \cdot 1$ & $5 \cdot 5 \pm 1 \cdot 8$ & $7 \cdot 8 \pm 1 \cdot 5$ & $6 \cdot 2 \pm 1 \cdot 9$ & $6.8 \pm 1.5$ & $4 \cdot 7 \pm 2 \cdot 4$ \\
\hline \multicolumn{7}{|l|}{ Thymidine } \\
\hline Trophoblast outgrowth & $13.9 \pm 1 \cdot 1$ & $14 \cdot 4 \pm 0 \cdot 6$ & $14 \cdot 2 \pm 0 \cdot 8$ & $14 \cdot 6 \pm 0 \cdot 6$ & $13 \cdot 0 \pm 1 \cdot 6$ & - \\
\hline Total ICMs & $11 \cdot 3 \pm 1 \cdot 8$ & $10 \cdot 6 \pm 1 \cdot 5$ & $3 \cdot 5 \pm 2 \cdot 2^{* *}$ & $1.8 \pm 0.5^{* *}$ & $1.0 \pm 1.4^{* *}$ & - \\
\hline ICMs with 2 germ layers & $5 \cdot 6 \pm 1.7$ & $5 \cdot 4 \pm 2 \cdot 3$ & $0.5 \pm 0.8^{* *}$ & $0^{* *}$ & $0^{* * *}$ & - \\
\hline
\end{tabular}

Significantly different from respective control value, $* P \leqslant 0.05 ; * * P \leqslant 0 \cdot 01$.

$10^{-4} \mathrm{M}$ and $P<00 \cdot 1$ for $10^{-3} \mathrm{M}$ ) as well as the total number of ICMs and the number of ICMs with two germ layers $(P<0.01)$. Inhibition of trophoblast outgrowth by guanosine was largely due to its interference with the attachment of denuded blastocysts: about $50 \%$ of denuded blastocysts failed to attach in the presence of $10^{-3} \mathrm{M}$-guanosine, whereas $100 \%$ of untreated denuded blastocysts attached. Adenosine was less toxic to embryos than thymidine or guanosine, but it inhibited development of ICMs at $10^{-2} \mathrm{M}(P<0 \cdot 01)$. Cytidine and uridine were not toxic to the embryos even at $10^{-2} \mathrm{M}$.

There was no additive effect when the five nucleosides were tested together at $10^{-6} \mathrm{M}$, the concentration at which none of the nucleosides was toxic to embryos (Table 2).

The lack of a stimulatory effect by exogenous nucleosides indicates that mouse blastocysts are capable of synthesizing the nucleic acid precursors which are necessary for their postimplantation growth in vitro. This lack of stimulation is probably not due to the inability of embryos to transport nucleosides across the cell membrane, because radioactive nucleosides are readily taken up into the

Table 2. Postimplantation development of mouse embryos (15 blastocysts for each experiment and 6 replicates of each) in the presence of $10^{-6} \mathrm{M}$ adenosine, cytidine, guanosine, thymidine uridine

\begin{tabular}{|c|c|c|c|c|}
\hline \multirow[b]{2}{*}{ Medium } & \multirow{2}{*}{$\begin{array}{l}\text { Serum } \\
\text { conc. } \\
(\%)\end{array}$} & \multicolumn{3}{|c|}{$\begin{array}{l}\text { Mean ( } \pm \text { S.E.M.) no. of embryos developing } \\
\text { to endpoints }\end{array}$} \\
\hline & & $\begin{array}{l}\text { Trophoblast } \\
\text { outgrowth }\end{array}$ & Total ICMs & $\begin{array}{l}\text { ICM with } 2 \\
\text { germ layers }\end{array}$ \\
\hline Control & 1 & $14.83 \pm 0.41$ & $12.67 \pm 2.88$ & $5.33 \pm 1.75$ \\
\hline Supplemented & 1 & $14.83 \pm 0.41$ & $12.03 \pm 1.64$ & $6.83 \pm 1.47$ \\
\hline Control & 10 & $14.07 \pm 0.52$ & $14.00 \pm 1 \cdot 10$ & $7.50 \pm 2.07$ \\
\hline Supplemented & 10 & $14.67 \pm 0.52$ & $13.67 \pm 1.03$ & $8.00 \pm 2.61$ \\
\hline
\end{tabular}


cells and incorporated into the RNA of mouse blastocysts (Daentl \& Epstein, 1971; Epstein \& Daentl, 1971) and the DNA of postimplantation-stage mouse embryos (Pedersen \& Cleaver, 1975). However, the synthesis of nucleic acids in cultured embryos may be limited by some other factors, such as an inadequate supply of folic acid or nicotinamide, which are constituents of coenzymes involved in nucleic acid synthesis (Friedkin, 1963; Laurent, Moor \& Reichard, 1964).

Exogenous nucleosides have also been found to be nonstimulatory or toxic to development of preimplantation mouse embryos in vitro (TenBroeck, 1968; Snow, 1973a). However, the toxic effect of nucleosides on postimplantation mouse embryos is different from that on preimplantation mouse embryos in three respects: thymidine is more toxic to postimplantation embryos (specifically to development of the ICM) than to preimplantation embryos, adenosine is less toxic than guanosine to postimplantation embryos but is more toxic than guanosine to preimplantation embryos, and cytidine and uridine are toxic only to preimplantation embryos. These differences may indicate differences in nucleic acid metabolism between pre- and postimplantation mouse embryos. Indeed, amino acids and serum are first required by blastocysts (Gwatkin, 1966; Spindle \& Pedersen, 1973), indicating that a marked change in embryo metabolism occurs at this stage of development.

The toxic effects of adenosine, guanosine and thymidine observed in this study, and the absence of such effects by cytidine and uridine, could reflect the regulatory roles that these nucleosides have in the inhibition of nucleic acid metabolic pathways. It has been shown that deoxyribonucleoside triphosphates of adenine, guanine and thymine inhibit DNA synthesis by interfering with the activity of ribonucleotide reductase but that deoxycytidine triphosphate does not (Reichard, Canellakis \& Canellakis, 1961).

The reason for the higher toxicity of guanosine than adenosine is not clear, but guanosine has also been shown to be more toxic than adenosine to 4-day-old chick embryos (Karnofsky \& Lacon, 1961). The inhibitory effect of guanosine on trophoblast outgrowth, which is probably due to attachment failure, is intriguing because treatments of blastocysts with thymidine and with various other agents (Snow, 1973b; Sherman \& Atienza, 1975; Glass, Spindle \& Pedersen, 1976; Pedersen \& Spindle, 1976) do not affect trophoblast outgrowth but severely interfere with the development of the ICM. Because omission of leucine or arginine from the medium also causes attachment failure of mouse blastocysts (Gwatkin, 1966; Spindle \& Pedersen, 1976), guanosine may be interfering with the synthesis of proteins that are needed for attachment of blastocysts.

We thank Dr M. Golbus for his comments on the manuscript. Work performed under the auspices of the U.S. Energy Research and Development Administration.

\section{References}

Daentl, D.L. \& Epstein, C.J. (1971) Developmental interrelationships of uridine uptake, nucleotide formation and incorporation into RNA by early mammalian embryos. Devl Biol. 24, 428-442.

EpsteIN, C.J. \& DaENTL, D.L. (1971) Precursor pools and RNA synthesis in preimplantation mouse embryos. Devl Biol. 26, 517-524.

FriedKIN, M. (1963) Enzymatic aspects of folic acid. A. Rev. Biochem. 32, 185-214.

Glass, R.H., Spindle, A.I. \& Pedersen, R.A. (1976) Differential inhibition of trophoblast outgrowth and inner cell mass growth by actinomycin $D$ in cultured mouse embryos. J. Reprod. Fert. 48, 443445.

Gwatkin, R.B.L. (1966) Amino acid requirements for attachment and outgrowth of the mouse blastocyst in vitro. J. cell. comp. Physiol. 68, 335-343.

Hsu, Y.-C. (1972) Differentiation in vitro of mouse embryos beyond the implantation stage. Nature, Lond. 239, 200-202.
Hsu, Y.-C., Baskar, J., Stevens, L.C. \& Rash, J.E, (1974) Development in vitro of mouse embryos from the two-cell egg stage to the early somite stage. $J$. Embryol. exp. Morph. 31, 235-245.

KaRnOFSKY, D.A. \& LACON, C.R. (1961) Effects of physiological purines on the development of the chick embryo. Biol. Pharmac. 7, 154-158.

Laurent, T.C., Moor, E.C. \& Reichard, P. (1964) Enzymatic synthesis of deoxyribonucleotides. IV. Isolation and characterization of thioredoxin, the hydrogen donor from Escherichia coli B. J. biol. Chem. 239, 3436-3443.

Pedersen, R.A. \& Cleaver, J.E. (1975) Repair of UV damage to DNA of implantation-stage mouse embryos in vitro. Expl Cell Res. 95, 247-253.

Pedersen, R.A. \& Spindle, A.I. (1976) Genetic effects on mammalian development during and after implantation. In Embryogenesis in Mammals, Ciba Foundn. Symp. No. 40, pp. 133-149. Elsevier, Amsterdam. 
Pienkowski, M., Solter, D. \& Koprowski, H. (1974) Early mouse embryos: growth and differentiation in vitro. Expl Cell Res. 85, 424-428.

Reichard, P., Canellakis, Z.N. \& Canellakis, E.S. (1961) Studies on a possible regulatory mechanism for the biosynthesis of deoxyribonucleic acid. J. biol. Chem. 236, 2514-2519.

Sherman, M.I. \& AtienzA, S.B. (1975) Effects of bromodeoxyuridine, cytosine arabinoside and Colcemid upon in vitro development of mouse blastocysts. J. Embryol. exp. Morph. 34, 467-484.

SNow, M.H.L. (1973a) Abnormal development of preimplantation mouse embryos grown in vitro with [ $\left.{ }^{3} \mathrm{H}\right]$ thymidine. J. Embryol. exp. Morph. 29, 601-615.

SNOw, M.H.L. (1973b) The differential effect of $\left[{ }^{3} \mathrm{H}\right]-$ thymidine upon two populations of cells in preimplantation mouse embryos. In The Cell Cycle in
Development and Differentiation, pp. 311-324. Eds M. Balls \& F. S. Billett. Cambridge University Press. SPINDle, A.I. \& GoldsteIN. L.S. (1975) Induced ovulation in mature mice and developmental capacity of the embryos in vitro. J. Reprod. Fert. 44, 113-116.

Spindle, A.I. \& Pedersen, R.A. (1973) Hatching, attachment, and outgrowth of mouse blastocysts in vitro: fixed nitrogen requirements. J. exp. Zool. 186, 305-318

TENBROEK, J.T. (1968) Effect of nucleosides and nucleoside bases on the development of pre-implantation mouse embryos in vitro. J. Reprod. Fert. 17, 571573.

WORDINGER, R.J. \& BRINSTER, R.L. (1976) Influence of reduced glucose levels on the in vitro hatching, attachment, and trophoblast outgrowth of the mouse blastocyst. Devl Biol. 53, 294-296.

Received 15 February 1977 